\title{
Introduction. The Immigration-Crime Connection: Competing Theoretical Perspectives
}

\author{
Scot Wortley
}

Published online: 15 October 2009

(C) Springer Science + Business Media B.V. 2009

\section{The "Myth" of Immigrant Criminality}

In 1994, following a highly publicized homicide involving a white female victim and a black male assailant, the Canadian media began to draw a direct connection between immigration and violent crime (Wortley 2003). One popular columnist, for example, wrote that "our culture is not used to this type of savagery" and that "this type of crime is the direct result of choosing too many of the wrong immigrants" (Blachford 1994: 3). Another reporter maintained that "White Canadians are understandably fed up with people they see as outsiders coming into their country and beating and killing them" (Maharaj 1994: 11). Of course, this type of mediadriven moral panic is not unique to Canada. Similar public pronouncements about the relationship between immigration and criminality have emerged throughout the histories of Europe, the United States, Australia, and other immigration-receiving regions (see Martinez 2008; Collins and Reid, this volume). Unfortunately, sensationalistic media coverage of crimes committed by immigrants and racial minorities appears to have had a strong impact on public opinion. Indeed, international research indicates that, in many Western nations, a high proportion of the general public believes that immigrants commit more crime than the native born (see Simon and Sikich 2007).

Importantly, the belief or hypothesis that immigration causes crime is being severely challenged by recent scholarship. Renowned sociologist Robert Sampson (2006), for example, has argued that the drop in crime that began in the United States in the early 1990s can be partially explained by increases in immigration. Indeed, a growing number of studies have produced findings that suggest that

\footnotetext{
S. Wortley $(\bowtie)$

Centre of Criminology, University of Toronto, 14 Queen's Park Crescent West, Toronto, ON,

Canada M5S-3K9

e-mail: scot.wortley@utoronto.ca
} 
immigrants are more law-abiding than the native born (see reviews in Martinez 2008; Martinez and Valenzuela 2006; Rumbaut and Ewing 2007; Yeager 1996). A particularly striking finding is that immigrants are even less likely to engage in crime when they reside in neighborhoods that are largely populated by other immigrants (Sampson 2006). In other words, whatever factors reduce criminality among recent immigrants are more pronounced in neighborhoods of high immigrant concentration. Nonetheless, there is also evidence that although first-generation immigrants may enjoy some resilience to criminal behavior and substance abuse, this resilience may deteriorate with time spent in the receiving country. However, recent research also indicates that "second-generation" immigrant populations do not have higher overall levels of criminality than those who have resided in their host nation for several generations (see Wacquant 2005; Morenoff and Astor 2006).

The negative relationship between immigration and crime has also recently been documented by a large survey (approximately 2,000 respondents) of high school students drawn from an ethnically diverse suburb of Toronto, Canada (Hagan et al. 2008). This study estimated the association between immigration status and the probability of engaging in delinquent behavior, statistically controlling for gender, age, social class, and racial background. The results indicate that, regardless of racial background, first-generation youth (defined as youth who immigrated after 12 years of age) and one-and-a-half generation youth (defined as youth who immigrated before age 12) are significantly less likely to engage in deviant activity than secondgeneration youth (defined as youth born in Canada but with parents who were born abroad) or native-born youth. Importantly, this Canadian study also found that, despite popular stereotypes, second-generation students are not more likely to engage in various forms of deviant activity and drug use than the native born. After discussing their research results within the context of the emerging international literature, the authors conclude that: "Although we are sceptical of the views on immigration that turn merely on cost-benefit analyses for the receiving state, if any such ledger is drawn up, it is clear that when it comes to crime, immigration is favourable for receiving states" (Hagan et al. 2008: 106-107).

It is important to note, however, that cross-national research has documented that the level of immigrant involvement in crime may be related to how well they are received by host nations. For example, Lynch and Simon (2007) examined the relationship between immigration and crime in seven nations. Some nations (the United States and Canada) were classified as "immigrant nations" where the volume of immigrants is high, barriers to entry low, and naturalization is encouraged. Others countries (including Japan, Germany, and France) were classified as "nonimmigrant nations." In these countries, the volume of immigration is relatively low, the barriers to entry are significant, and permanent settlement is not encouraged. The results of this research project found that, in general, "immigrant countries" have significantly lower ratios of immigrant to native-born crime than "nonimmigrant" nations. The authors hypothesize that this finding may be due to the ability of "immigrant nations" to more fully integrate newcomers into mainstream society.

Although an increasing number of studies have documented that first-generation and second-generation immigrants are not more involved in crime than the native born, research has also consistently documented that some racial/ethnic groups are significantly over-represented in both official and unofficial crime statistics (see 
Peterson et al. 2006; Bowling and Phillips 2002; Wortley 2008). Research has also documented that, at certain times and places, specific immigrant groups appear to be more involved in criminality than others. For example, Rattner (2007) found that immigrant Russians in Israel do commit crime at a higher rate than native Israelis. Siegel and Bovenkerk (2007) also found that Russian immigrants are responsible for most of the organized crime in The Netherlands. Similarly, Jones (2007) documents how "Jamaican posses" emerged out of the economic and political turmoil of their homeland to establish a far-reaching, transnational criminal network that engages in gun running, drug trafficking, and money laundering.

Much of the policy discussion concerning immigration, ethnicity, and crime has focused on the issues of gangs, organized crime, and terrorism. Canadian police officials, for example, have attributed the recent spike in violent crime in the Vancouver area to the activities of both Asian and Indo-Canadian gangs (Kirby and Macdonald 2008). Even a casual review of the historical record reveals that this concern over immigration and gang activity is not new. During the late nineteenth century, for example, the North American focus was on crimes committed by Jewish, German, Polish, and Irish immigrant gangs. Today, the focus in much of Europe and North America has turned to gangs from Africa, the Caribbean, Asia, Russia, and the Middle East (see Decker, van Gemert, and Pyrooz, this volume).

Research on upper-level drug trafficking in North America, Britain, and The Netherlands suggests that issues of trust and friendship may help explain why some gangs or organized crime groups are restricted to specific ethnic or racial groups (Desroches 2007). Drug traffickers often operate through informal and loosely organized associations of "independent entrepreneurs." Individual traffickers compete for their market share and usually deal exclusively with trusted contacts drawn from the same ethnic background. Interviews with drug dealers, for example, have found that most dealers and their associates have pre-existing relationships based on race, ethnicity, or kinship bonds. Ethnic bonds also act as opportunity structures through which new dealers are taught the "tricks of the trade." Ethnicity can also play a prominent role when cultural ties in source countries are used to assist in the importation of narcotics. Interestingly, although strong ethnic and kinship networks may help maintain security for upper-level drug traffickers, they can also limit opportunity within the drug economy. Desroches (2007) found, for example, that some drug dealers actually pass up lucrative opportunities to expand their drug business because they are uncomfortable working with people outside of their trusted circle of ethnic relations.

\section{Examining the Immigration-Crime Connection}

Unfortunately, the available research on immigration, ethnicity, and crime is rather limited. Data that enable cross-national comparisons with respect to this issue are particularly hard to locate. Indeed, many nations simply do not, on a regular basis, break down their aggregate crime statistics by immigration status or ethnicity. Thus, the data we do have typically produces many more questions than they answer. What immigrant/ethnic groups are most and least involved in crime? Does the relationship between immigration, ethnicity, and crime vary from nation to nation? What types of 
crimes are immigrants and ethnic minorities most likely to be involved with? Do ethnic patterns of criminal behavior vary over time and place? Why do some immigrant/ethnic groups appear to be more involved in criminal activity than others? Does the criminal justice system treat immigrants and ethnic minorities the same as the native born?

The six papers presented in this volume directly contribute to the discussion of various issues related to immigration, crime, and justice. In the following section, I briefly describe these papers and attempt to locate them within one of four explanatory frameworks: (1) the importation model; (2) the strain model; (3) the cultural conflict model; and (4) the bias model. Each of these models provides a very different framework from which to examine the connection between immigration, ethnicity, and crime. These four models also vary dramatically with respect to their policy implications (see Wortley 2004).

\section{The Importation Model}

The importation model focuses explicitly on the relationship between migration and crime. It assumes that some individuals make the decision to migrate with the explicit objective of engaging in criminal activity within the receiving country. This model is often used to explain the presence of international crime syndicates, criminal gangs, and terrorist organizations. These organizations, it is argued, frequently engage in various forms of illegal activity including drug trafficking, fraud, human trafficking, theft, smuggling, extortion, home invasions, prostitution, and terrorism. Policy initiatives associated with importation model include improved screening of potential immigrants and refugees, better tracking of international criminals through cooperation with foreign police agencies, the restriction of immigration from "crime-prone" countries, and the swift deportation of immigrants who are convicted of criminal offenses. Clearly, the importation model may appeal to conservative policy-makers because it largely absolves the host society of responsibility for immigrant and/or ethnic minority crime. Indeed, this theory holds that immigrant, minority offenders are already motivated criminals when they make the decision to migrate.

In this volume, Annmarie Barnes describes how the "importation" perspective contributed to a moral panic over Jamaican immigrant criminality in Canada. This moral panic, in turn, led to the toughening of Canadian laws justifying the deportation of noncitizens convicted of criminal offenses. Similar deportation laws have been passed in many other immigrant-receiving nations. Barnes then documents the large number of criminal deportees that have been "removed" to Jamaica over the past decade from Canada, the United States, and Great Britain. These deportations, it is argued, have directly contributed to various economic, social, and security problems within this Caribbean nation. Importantly, Barnes also documents the catastrophic impact that criminal deportation can have on the deportees themselves. The difficulties faced by deportees include loss of family and support networks, social stigmatization, economic hardship, depression, hopelessness, and alienation. Those deportees who emigrated from Jamaica as young children and were returned as adults seem to suffer the greatest hardships. Interestingly, banishment and transportation have long been dismissed as unjust or 
even barbaric by penal scholars. As such, these methods of punishment have been largely eliminated from the formal criminal codes of most Western democracies. The phenomenon of criminal deportation, however, reveals that these methods of punishment are still widely used against vulnerable immigrant populations. Western nations also appear to have little concern for the problems that criminal deportation can have on the developing world.

\section{The Strain Model}

Unlike the importation model, the strain model recognizes that the process of migration and resettlement is often stressful. It further maintains that it is the experiences of immigrants within host societies that are the primary cause of immigrant and ethnic minority crime. It is argued that immigrants - especially racial minority immigrants - frequently suffer from social, cultural, political, and economic marginalization. Indeed, a wealth of research suggests that immigrants experience higher than average levels of unemployment, low household incomes, and often suffer from discrimination and institutional barriers with respect to housing, education, career opportunities, and political participation (see Wortley 2004). It is argued that these negative life experiences produce both absolute and relative deprivation and that such deprivation can push some people towards criminal activity. For example, impoverished immigrant youth who feel alienated from mainstream society may turn to youth gangs for both social acceptance and economic gain. Indeed, organized crime may directly benefit from the alienation of recent immigrants. Those who are disillusioned and frustrated with mainstream society are much more likely to be attracted to the illegitimate economic opportunities provided by such organizations. Poverty and deprivation may also cause some racial minority mothers to engage in petty theft and shoplifting in order to feed or clothe their children. Likewise, the extreme frustration caused by personal experiences of discrimination and joblessness may lead some men to engage in certain forms of expressive violence.

Overall, the strain model is highly consistent with many of the classic theories of crime causation (Anomie Theory, Social Disorganization Theory, Relative Deprivation Theory, Rational Choice Theory, Neutralization Theory, etc.) which draw a direct line between criminal behavior and conditions of poverty, frustration, and hopelessness (see reviews in Siegel and McCormick 2003; Linden 2009). According to this perspective, once researchers have empirically controlled for conditions of absolute and relative deprivation, any correlation between immigration and criminal behavior will disappear. In sum, the strain model takes the responsibility for crime away from the immigrant - and their country of origin - and puts it squarely on negative settlement processes within host nations. As a result, the strain model produces radically different policy options. Rather than focus on law enforcement initiatives, this perspective suggests that immigrant crime will be only reduced by policies that eliminate discrimination, reduce economic inequality, and increase both educational and employment opportunities.

Several of the articles presented in this volume are highly consistent with the "strain" perspective. Rossitor and Rossitor, for example, conducted interviews with professional stakeholders who frequently come into contact with immigrant youth 
who have engaged in serious criminal activity. In general, these stakeholders are in agreement that poverty (at both the family and community level), language barriers, cultural isolation, discrimination, and social alienation are the risk factors most highly associated with immigrant youth criminality. Protective factors include strong family ties, school attachment, religion, prosocial peers, and enhanced cultural identify. The authors conclude their paper with a discussion of policy initiatives that could improve the settlement experience for newcomers and subsequently prevent immigrant and refugee youth from engaging in crime.

Collins and Reid also acknowledge that, in Australia, immigrant youth and their families often suffer from both economic and social marginalization. These risk factors, they argue, can at times result in immigrant crime. However, they also maintain that evidence of immigrant youth criminality is grossly exaggerated within Australian society and that both media discourse and political opportunism have contributed to the negative stereotyping of entire ethnic communities. These negative stereotypes, in turn, have been used to justify public spending on law enforcement and national security initiatives, while at the same time drawing policy attention away from strategies that would address immigrant and minority poverty. The authors use the example of the Sydney Cronulla Beach riots to further demonstrate that the perpetuation of racist stereotypes can directly contribute to interethnic tensions and conflict. Nonetheless, the authors argue that interethnic conflict in Australia is the exception, not the rule. Indeed, their analysis of previously unpublished survey data indicates that minority youth in Australia are not socially alienated and tend to hold "cosmopolitan" identities. They are connected to family, to friends (often from outside their own ethnicity), and to their local community. However, compared to white Australians, they are less connected to the flag and express significantly less pride in Australian citizenship.

\section{The Cultural Conflict Model}

The cultural conflict model focuses on the complex intersection between immigration and culture. This explanatory framework holds that the vast majority of immigrants arrive in their host country with absolutely no intention of engaging in criminal activity. It is argued, however, that some recent immigrants maintain cultural or religious practices which come into conflict with the laws or customs in their new home. For example, some cultures may condone certain forms of domestic violence as a means of ensuring strict adherence to religious scriptures. While these forms of corporal punishment may be acceptable in their country of origin, such behavior may warrant criminal charges in the host nation. Similarly, prostitution and the use of certain drugs may be culturally acceptable in some countries, but violate the law in Canada, the United States, and most of Europe. Gambling is yet another cultural practice which may bring some minority groups into conflict with legal authorities (see discussion in Yeager 1996). Clearly, policy initiatives based on this model should, therefore, focus on either: (1) educating potential immigrants about the criminal law before they actually make the decision to immigrate or (2) informing or educating recent immigrants about how certain cultural or religious traditions associated with their group may lead to conflicts with the law. Thus, under this model, the legal education of new arrivals is a more important policy option than heightened border security. 
In this volume, Decker, van Gemert, and Pyrooz highlight the importance of culture in explaining the existence of ethnic gangs in immigrant-receiving nations. Consistent with the strain perspective, the authors first highlight that both American and European researchers have identified common macro-level factors that are highly associated with gang formation. These macro-level factors include various measures of economic disadvantage and social disorganization. However, the authors note that these structural variables do not always result in gang activity. Indeed, faced with similar immigration histories and economic challenges, gangs sometimes take root among some ethnic groups but not others. The nature of gang activity - including the extent of criminal involvement - can also vary dramatically from country to country and from community to community. In order to explain these regional and ethnic group differences, the authors maintain that we must consider micro-level cultural conflicts that emerge within specific neighborhoods. In conclusion, the authors maintain that how immigrant groups are treated by the indigenous population and how they interact with other ethnic groups in local communities that will determine the "local flavor" of gang activity. The authors also discuss how the global media - including the movie and music industries - have disseminated elements of American gang culture (including street gang names and symbols) throughout the world. They stress, however, that most of media impact is superficial. Gangs are much more influenced by local conditions and culture than by media images.

\section{The Bias Model}

The importation, strain, and cultural conflict models all anticipate that any observed relationship between immigration and crime can be explained by complex interactions between economic deprivation, social alienation, and culture. Furthermore, although these three models have fundamentally different theoretical foundations, they seem to take for granted that certain immigrant or ethnic groups are actually more involved in crime than others. By contrast, the bias model argues that any over-representation of immigrants or ethnic minorities in crime statistics may not be the result of actual differences in criminal behavior. Rather, such differences may be the result of overt and systemic discrimination within the criminal justice system. In other words, certain immigrant/ethnic minority groups may be over-represented in crime statistics because, compared to the native born, they are more likely to come under intense police surveillance (racial profiling), more likely to be arrested by the police, and more likely to be convicted and given tough sentences by the criminal courts.

Using data from a 2007 general population survey, Wortley and Owusu-Bempah (this volume) clearly demonstrate that perceptions of discrimination within the criminal justice system are widespread among certain segments of the Canadian population. Black Canadians, for example, are much more likely to perceive racial discrimination in policing and the criminal courts than the members of other racial groups. Importantly, the authors also find that immigration status cannot explain these racial differences. Indeed, recent immigrants tend to have the most positive opinions about the Canadian criminal justice system. However, perceptions of the police and criminal courts become more negative with time spent in Canada and are 
most unfavorable among Black and Chinese respondents who are native born. The authors then review competing explanations for why negative perceptions of the justice system develop among certain ethnic groups and discuss the policy implications of their findings. They stress that perceptions of the justice system should not be taken lightly by immigration researchers or criminal justice officials. Negative perceptions may impede citizens from cooperating in criminal investigations and ultimately can be used to justify criminal behavior.

In his literature review, Rob White documents the negative nature of policeminority relations in Australia. White argues that moral panics surrounding immigrant minority crime have often been used to justify coercive, zero tolerance police strategies in Australia and other Western nations. These aggressive policing strategies, he argues, greatly increase the number of unpleasant interactions between the police and immigrant youth and subsequently contribute to negative perceptions of the host society-particularly the criminal justice system - within immigrant communities. Similar to Wortley and Owusu-Bempah, White also argues that aggressive policing may produce a self-fulfilling prophecy by directly contributing to the types of immigrant youth alienation that can result in criminal activity. White, however, concludes his paper on a promising note by maintaining that new community policing strategies can bridge the gap between the police and ethnic minority communities and ultimately assist immigrants during the resettlement process. Unfortunately, the effectiveness of such community policing efforts has yet to be fully evaluated (see also Stenning 2003).

\section{Conclusion}

The papers presented in this special edition are designed to provoke academic debate and policy discussion with respect to the often controversial issue of migration, crime, and justice. Clearly, the authors whose work is presented in the following pages have only tapped the surface of this extremely important topic. As discussed above, there are many more research questions that have yet to be adequately addressed by empirical study. It is also clear that if these research questions are to be thoroughly examined, a stronger alliance needs to be developed between academic researchers on the one hand and representatives from Western justice systems on the other. Policy-makers within the justice system, I believe, can greatly benefit from the objective and research expertise that is present within the academic community. On the other hand, academics would greatly benefit from greater access to criminal justice data and research opportunities. Hopefully, this form of cooperation will develop in the near future. As articulated by Freilich and Newman (2007: xv): "Far more research is needed on every aspect of migration as it relates to crime and justice. A sensible start would be for countries to begin systemically to collect information on immigrants so that research related to the many problems relating to immigrant crime and victimization could be addressed... Without research based on valid and reliable data, government policies are destined to remain deeply political and divisive. In fact, such policies become part of the problem rather than its solution." 
Acknowledgements We would like to thank Austin Lawrence for finding funding for this Special Issue, and Steve Morris (now retired from Metropolis Canada) for contributing to the start-up of the issue. We would also like to acknowledge Justice Canada for their contribution to this Special Issue.

\section{References}

Blachford, C. (1994). Good vs. evil. Toronto Sun, 8, 3.

Bowling, B., \& Phillips, C. (2002). Racism, crime and justice. Britain: Pearson Education.

Desroches, F. (2007). Research on upper-level drug traffickers: A review. Journal of Drug Issues, 37(4), $827-844$

Freilich, J., \& Newman, G. (2007). Crime and immigration. Burlington: Ashgate.

Hagan, J., Levi, R., \& Dinovitzer, R. (2008). The symbolic violence of the crime-immigration nexus: Migrant mythologies in the Americas. Criminology and Public Policy, 7(1), 95-112.

Jones, M. (2007). Policy paradox: Implications of U.S. drug control policy for Jamaica. In J. Freilich \& G. Newman (Eds.), Crime and immigration (pp. 53-70). Burlington: Ashgate.

Kirby, J., \& MacDonald, N. (2008). How British Columbia became a world crime superpower. Maclean's, 121(19), 22-27.

Linden, R. (2009). Criminology: A Canadian Perspective (6th Edition). Toronto: Nelson.

Lynch, J., \& Simon, R. (2007). A comparative assessment of criminal involvement among immigrants and natives across seven nations. In J. Freilich \& G. Newman (Eds.), Crime and immigration (pp. 273290). Burlington: Ashgate.

Maharaj, R. (1994). Crime crosses all barriers. Toronto Sun, 15, 11.

Martinez, R. (2008). Immigration, crime and recidivism: Editorial introduction. Criminology and Public Policy, 7(1), 53-58.

Martinez, R., \& Valenzuela, A. (2006). Coming to America: Immigration, ethnicity and crime. New York: New York University Press.

Morenoff, J., \& Astor, A. (2006). Immigrant assimilation and crime. In R. Martinez \& A. Valenzuela (Eds.), Coming to America: Immigration, ethnicity and crime. New York: New York University Press.

Peterson, R., Krivo, L., \& Hagan, J. (2006). The many colours of crime: Inequalities of race, ethnicity and crime in America. New York: New York University Press.

Rattner, A. (2007). Crime and Russian immigration: Socialization or importation? The Israeli case. In J. Freilich \& G. Newman (Eds.), Crime and immigration (pp. 165-178). Burlington: Ashgate.

Rumbaut, R. \& Ewing, W. (2007). The myth of immigrant criminality. Retrieved from http://borderbattles. ssrc.org/Rumbaut_Ewing/index.html.

Sampson, R. (2006). Open doors don't invite criminals: Is increased immigration behind the drop in crime? The New York Times (March 11), A27.

Siegel, D., \& Bovenkerk, F. (2007). Crime and manipulation of identity among Russian-speaking immigrants in the Netherlands. In J. Freilich \& G. Newman (Eds.), Crime and immigration (pp. 251272). Burlington: Ashgate.

Siegel, L., \& McCormick, C. (2003). Criminology in Canada: Theories, patterns and typologies. Toronto: Thompson-Nelson.

Simon, R., \& Sikich, K. (2007). Public attitudes toward immigrants and immigration policies across seven nations. International Migration Review, 41(4), 956-962.

Stenning, P. (2003). Policing the cultural kaleidoscope: Recent Canadian experience. Police and Society, 7, 21-87.

Wacquant, L. (2005). Enemies of the wholesome part of the nation: Postcolonial migrants in the prisons of Europe. Sociologie, 1, 31-51.

Wortley, S. (2003). Misrepresentation or reality: The depiction of race and crime in the Canadian print media. In B. Schissel \& C. Brooks (Eds.), Critical criminology in Canada: Breaking the links between marginality and condemnation (pp. 87-111). Halifax: Fernwood Press.

Wortley, S. (2004). Hidden intersections: Research on race, crime and criminal justice in Canada. Canadian Ethnic Studies Journal, 35(3), 99-117.

Wortley, S. (2008). A province at the crossroads: Statistics on youth violence in Ontario. In R. McMurtry $\&$ A. Curling (Eds.), The review of the roots of youth violence (volume 4) (pp. 1-64). Toronto: Queens Printer for Ontario.

Yeager, M. (1996). Immigrants and criminality: A meta survey. Ottawa: The Metropolis Project. 
Dr. Wortley has been a Professor at the Centre of Criminology, University of Toronto since 1996. In 2001, he was appointed the Justice and Law Domain Leader at the Centre of Excellence for Research on Immigration and Settlement (CERIS). In 2007, he was appointed by Metropolis to the position of National Priority Leader for research on Justice, Policing and Security. His current research interests include immigration and crime, discrimination within the criminal justice system, public perceptions of the police, courts and corrections, criminal offending, gang membership and victimization in both Canada and the Caribbean and the effectiveness of crime prevention strategies. 